

\title{
O JARDIM DA VILLA STEIN-DE MONZIE: UM PROJETO DE LE CORBUSIER E PIERRE JEANNERET (VERSÃO DE 1926)
}

\author{
THE VILLA STEIN-DE MONZIE GARDEN: A PROJECT BY LE CORBUSIER AND PIERRE \\ JEANNERET (1926)
}

\begin{abstract}
Silvia Odebrecht
Arquiteta e professora no curso de Arquitetura e Urbanismo da Universidade Regional de Blumenau FURB e doutora pela Escuela Técnica Superior de Arquitectura de Valladolid, Espanha, em Modernidad Contemporaneidad en la Arquitectura.

e-mail: siba@furb.br
\end{abstract}

\section{RESUMO}

O presente artigo aborda uma análise pouco trabalhada na literatura especializada, sobre o jardim da Villa Stein-de Monzie, também conhecida como Les Terrasses, na versão de 1926, desenvolvida por Le Corbusier e Pierre Jeanneret. Esse jardim não foi construído e essa pode ser uma das principais causas por não se encontrar uma documentação gráfica completa de seu projeto. A detalhada descrição aqui apresentada permite imaginar como teria ficado a propriedade de Les Terrasses se o projeto do jardim tivesse sido executado. A reflexão deste trabalho é uma lição sobre história da arquitetura, sobre a obra de Le Corbusier e Pierre Jeanneret e uma referência à pesquisa sobre o paisagismo moderno.

Palavras-chave: Paisagismo, modernidade, jardim, Le Corbusier, Pierre Jeanneret, Villa Stein-de Monzie, Les Terrasses.

\begin{abstract}
It is submitted an analysis and reflexions on the Villa Stein-de Monzie, a project by Le Corbusier and Pierre Jeanneret developed in 1926 with special emphasis in their proposal for the garden at level 0,0. But this project never been built, however the new concepts applied in it and probably, due to this, there is no so much literature about the project. The author does professional and astute suppositions that permit us to imagine and to walk in the today's inexistent garden. Without doubts in this paper it is possible find an interested lesson of history of architecture, in particular about the Le Corbusier heritage and his collaborator Pierre Jeanneret and a reference to research on the modern landscape.
\end{abstract}

Key words: Landscape, modernity, garden, Le Corbusier, Pierre Jeanneret, Villa Stein-de Monzie, Les Terrasses.

\section{INTRODUÇÃO}

Este trabalho é uma análise e reflexão sobre o jardim da Villa Stein-de Monzie, em sua versão de 1926, projetado para a residência unifamiliar de Michael e Sarah Stein e Gabrielle de Monzie, também conhecida como Villa Les Terrasses, um projeto de Le Corbusier e Pierre Jeanneret, para um terreno situado nos subúrbios de Paris, em Garches. $\bigcirc$ projeto dessa residência já foi exaustivamente analisado por vários estudiosos, que raramente incluíram o jardim como parte integrante do projeto. Isso 
provavelmente se deve ao fato de o projeto do lote só aparecer claramente na versão de 1926, anterior ao projeto final da casa. Mas é exatamente essa versão que se torna especial, por se tratar de um dos poucos projetos de jardim, no nível do solo, que Le Corbusier elaborou com tantos detalhes.

Essa versão do jardim não foi executada. A versão realizada sofreu significativas alterações. Imbert (1993, p. 156) comenta que o motivo do contraste existente entre o jardim ortogonal projetado e o casual realizado permanece incógnito. A versão analisada trata de uma proposta que reflete os fundamentos conceituais de arquitetura, de plástica e de desenho da época e, principalmente, as novas idéias de Le Corbusier.

interesse de Le Corbusier pela utilização do espaço aberto de jardim ocorreu de várias maneiras. Definiu seu conceito de cidade pensando em construí-la em um parque. Trabalhou os conceitos de jardim urbano e de jardim suspenso. Definiu um modelo de casa, no qual o jardim de cobertura era um dos pontos fundamentais. Os croquis de seus projetos sempre contaram com elementos de vegetação. As árvores e os arbustos eram para ele considerados como um complemento necessário às suas obras. Hoje, no entanto, não temos a possibilidade de apreciar suas idéias sobre o jardim, pois essas, ou não foram executadas ou foram modificadas, ou abandonadas e malreformadas.

No verão de 1915 na Biblioteca Nacional da França, Le Corbusier se dedicou a estudar vários tratados de paisagismo, familiarizando-se com o vocabulário do jardim francês. Além das pesquisas dos tradicionais jardins franceses e de seus canteiros sazonais, também manteve contato com os escritos de André Vera, de um jardim novo que difundia o desejo de ordem, limpeza e clareza em todas as coisas. Buscou, ainda, alguns conhecimentos na botânica, devido ao seu interesse pela tipologia vegetal. No entanto, existem poucos registros gravados de suas pesquisas sobre jardins.

Já em termos de urbanismo temos uma bibliografia mais farta. $\bigcirc$ arquiteto acreditava que a cidade do amanhã devesse estar situada entre um meio mais verde e as árvores funcionassem como pulmão e ainda realçassem a modelagem geométrica da arquitetura. Mas criticava o uso da vegetação quando empregada como uma camuflagem, comprometendo a obra por meio de uma ilusão ou sua obstrução. A idéia de Le Corbusier que não só os grandes jardins extravagantes e magníficos tivessem sua importância, mas também que os pequenos pudessem ser elaborados com qualidade, algo difícil de compreender no início do século 20. Assim, Le Corbusier surpreendeu o mundo, em 1925, com sua obra do pavilhão de L'Espirit Nouveau, na Exposição Internacional de Artes Decorativas e Industriais Modernas, em Paris. Esse pavilhão foi construído ao redor de uma árvore existente, que se projetava além da edificação por uma abertura circular na laje de cobertura. Era a idéia de trazer o jardim para dentro de casa por meio de um terraço espaçoso e individualizado pertencente a uma unidade residencial. Esse era um elemento novo, utilizado pela primeira vez em um edifício residencial multifamiliar, o Immeuble Villa.

Conforme Brown (2000, p. 20), o pavilhão de L'Espirit Nouveau introduz duas idéias importantes: (1) a hipótese de Le Corbusier de as novas gerações somente quererem 
um paisagismo "passivo", para relaxar e desfrutar das visuais; (2) e a contemplação da paisagem pudesse ocorrer através de retângulos, nesse caso, do balcão aberto ou das janelas, como moldura de uma tela. Trata-se da eternização da paisagem por meio de um quadro, tornando-a estática como uma natureza morta, uma natureza dominada pelo homem, na qual a geometria racional aprisiona o orgânico, o selvagem, o emocional.

Por outro lado, Le Corbusier tinha idéias democráticas para o jardim, acreditando no direito básico de sol, ar e vegetação para todos. Com o advento dos novos métodos construtivos, de aço e concreto armado, isso poderia se tornar possível, na medida em que pequenos apartamentos também pudessem ter, cada um, seu jardim privado, assim como as ricas residências unifamiliares pudessem ter seus jardins suspensos.

\section{EVOLUÇÃO DO PROJETO}

Um projeto não nasce pronto, normalmente passa por uma série de alterações e adaptações. A Villa Stein também passou por esse processo, no qual se pode claramente perceber três etapas distintas, conforme os croquis e desenhos encontrados. Em uma proposta inicial já é possível perceber as diretrizes gerais do projeto, como a localização central da casa em relação ao terreno, dividindo-o em dois setores de jardim. Nessa proposta a setorização era, todavia, mais forte do que na versão de 1926, pois a casa ocupava o terreno de divisa a divisa. Os terraços dessa versão, bem como os do projeto final, tinham a função de proporcionar uma inter-relação dos espaços internos com os externos. Inicialmente também já aparecem as linhas curvas que se contrapõem com a retícula ortogonal dominante; nesse caso, um trabalho escultórico na cobertura, transformando esse terraço em um importante símbolo de liberdade e de um novo estilo de vida.

Na versão de 1926 já estavam incorporados ao projeto a idéia do bosque, do jardim mais livre nos fundos e da quadrícula muito rígida com um jardim formal na frente. $\bigcirc$ acesso de veículos proporcionava uma visual um pouco menos evidente da casa do que no projeto final, pela posição de algumas árvores que depois foram deslocadas para destacar mais a fachada. Também permaneceram presentes, no projeto, as duas espécies vegetais que, de forma escultórica, teriam a função de enquadrar a entrada principal. $\bigcirc$ volume anexo, construído na divisa com o intuito de bloquear a visual para a piscina vizinha, foi mais tarde substituído por uma massa de vegetação.

Podemos considerar como uma segunda etapa o projeto do jardim datado de 13 de novembro de 1926, para o qual foi elaborada uma refinada composição gráfica, em que são definidas áreas com diferentes densidades, equilibrando cheios e vazios. Trata-se do projeto a ser estudado aqui, do qual existe uma detalhada planta baixa.

E, uma terceira e última etapa, o jardim executado. Conforme desenho em Brown (op. cit., p. 20), esse jardim possui uma caracterização menos evidente da regularidade entre massas e vazios e com uma vegetação mais dispersa e menos organizada, tanto nos fundos como na frente da casa. A alteração da entrada eliminou a reticulada horta. 
Também foi abolido o organizado pomar. $\bigcirc$ eixo do acesso de veículos foi alterado, dirigindo-se agora ao centro da entrada de serviço e não mais ao centro da garagem. Dessa forma, fica evidente a completa alteração do projeto que havia sido elaborado tão criteriosamente. $\bigcirc$ jardim executado foi radicalmente simplificado.

\section{DESCRIÇÃO DO JARDIM (VERSÃO DE 1926)}

O jardim da Villa Stein é um dos mais interessantes, complexos e detalhados projetos de paisagismo de Le Corbusier. Nele a casa aparece como um elemento de composição, no qual a estrutura geométrica da planta baixa é transportada para o desenho do jardim. Isso proporciona à planta do jardim uma distribuição de espaços segundo os eixos, a retícula e as regras rígidas de composição da casa, levando, aos espaços externos, o princípio de ordem e o formalismo estético. $\bigcirc$ estudo das proporções que definiu o traçado regulador das fachadas está presente no jardim, evidenciado pelo desenho dos caminhos retilíneos e dos espaços geometricamente ordenados. Apesar de o desenho do jardim obedecer ao traçado da casa, isso não compromete a funcionalidade de seu uso, que tem relevante importância em sua configuração. As várias funções que se distribuem em seus espaços se interligam por uma circulação natural, implantada pelos caminhos estrategicamente posicionados. Dessa maneira, o desenho do jardim se articula com a edificação, pela forma e pela função, por meio do traçado de seus caminhos.

Também a linguagem de composição da casa é transportada para o jardim. $\mathrm{Na}$ casa, as massas contrastam com os ocos interiores, os espaços abertos de pé-direito alto. No jardim, a volumetria da vegetação é utilizada como um elemento construído, dispondo-se de maneira a formar espaços de massas e vazios, em um desenho intercalado, rítmico. Dessa forma, o jardim é concebido em continuidade com a arquitetura, além de envolver a casa, enquadrando-a e valorizando-a, sempre em harmonia com ela. Os terraços induzem à fusão do jardim com a casa, fazendo com que os espaços internos e os externos se confundam.

A casa se localiza no centro de um terreno estreito e comprido, completamente plano, comportando-se como um elemento divisor entre a zona pública, de utilidade, e o jardim privado, ou seja, entre a área do automóvel na frente e a área íntima nos fundos. Como a casa contempla um terraço de cobertura, que também se comporta como um jardim por seus maciços de vegetação em floreiras, pode-se dizer que o projeto possui três zonas de jardim com características bastante distintas. $\bigcirc$ jardim frontal possui um desenho extremamente formal, geométrico, com caminhos retilíneos e árvores plantadas em fileiras. Já o posterior possui um desenho menos rígido, mais informal, com a plantação da vegetação mais livre e um caminho sinuoso. Uma formalidade descontraída. Todavia, percebe-se um equilíbrio conferido à importância das duas funções: a de dirigir e a de estar e passear.

No jardim frontal, o acesso ao lote ocupa uma posição de eixo em relação à garagem, proporcionando, ao entrar e ao longo do caminho, uma contemplação geral da 
fachada da casa. Uma grande área vazia na frente, tal qual uma esplanada, possibilita a contemplação dessa fachada. O grande vazio da esplanada se identifica com o grande vazio interior existente na casa e representa, ainda, o rebatimento de sua fachada sobre o solo, como se fosse sua sombra. A área necessária para essa esplanada foi cuidadosamente estudada para que o veículo pudesse confortavelmente fazer a volta e retornar ao portão de acesso.

Junto da casa, entre os acessos social e de serviço, existe um pequeno jardim disposto em forma de canteiros. $\bigcirc$ acesso à porta de serviço está delimitado nos dois lados por uma vegetação arbustiva em topiária e, na frente, por um pequeno muro, proporcionando uma entrada confinada. Uma fileira de cinco árvores de cada lado, simetricamente dispostas, emolduram a edificação e valorizam-na pelo contraste entre o verde da vegetação e o branco volume construído. Dois elementos arquitetônicos, posicionados de forma simétrica e demarcando a porta principal, têm, provavelmente, a função de pedestal para alguma escultura. No mesmo alinhamento foram colocadas em destaque duas espécies vegetais que, conforme o croqui de um estudo preliminar, define uma forma escultórica evidenciando-se das outras espécies.

O caminho retilíneo para veículos, que conduz ao acesso frontal da casa, está ladeado por uma vegetação mediana, provavelmente a ser podada ao modo de topiária. No lado direito desse caminho, para quem se posiciona de frente à casa, está o pomar, formando um maciço de vegetação plantada em linhas e definindo uma malha. Mais para frente está a horta, com aspecto de jardim e organizada em canteiros retangulares. A definição da vegetação observou, ainda, uma cuidadosa proteção visual em relação aos vizinhos. Para esconder a visual indesejável de uma edificação construída na divisa, ou para bloquear a visual sobre a área da piscina vizinha, foram plantadas árvores de folhas perenes.

No acesso ao lote existe uma pequena edificação, com função de recepção ou guarita, onde também se encontra o portão e uma cobertura plana para proteção contra as intempéries e demarcação da entrada, a modo de pórtico. Segundo Imbert (op. cit., p. 155), essa portaria com um espaço livre frontal foi adotado por Le Corbusier, a partir de um modelo típico para uma propriedade no campo.

Voltado para o lazer e para a natureza, o jardim posterior propõe uma integração com os terraços e com os grandes vãos abertos da edificação, penetrando por eles e pelos panos de vidro nos espaços da casa. $\bigcirc$ jardim inicia com uma composição que configura a continuação do desenho da casa, com um caminho retilíneo definido por um dos eixos da construção. Esse caminho conduz a um elemento arquitetônico, do qual não foi encontrada documentação volumétrica. A partir da planta baixa, e por um estudo das possibilidades, chegou-se à proposta de uma janela-quadro, tal qual similares encontradas em vários projetos de Le Corbusier, e também no jardim de cobertura, bem como em uma parede lateral da Villa Stein. Esse elemento poderia contemplar ainda uma mesa posicionada junto da janela. A partir desse elemento a vegetação toma outra configuração, apresentando-se de forma naturalista, com uma plantação livre em forma de bosque. 
Próximo à edificação abre-se um grande espaço, uma área gramada, caracterizando um vazio volumétrico. Seu objetivo era possibilitar, a partir do jardim, a visualização da casa como foco principal, sem a interferência de qualquer elemento a não ser a janela-quadro que fornece uma moldura para a casa.

Da mesma forma como surgem as curvas nas plantas da casa, um caminho sinuoso, induzindo ao passeio, quebra a rigidez da composição, que, de forma intencionada, introduz um movimento de liberdade que interrompe e transcende à quadrícula, fugindo dos eixos e delineando-se com muita força e elegância. Mas essa liberdade se dá de forma controlada, pois o caminho sinuoso se apresenta ancorado por uma pavimentação rigorosamente no esquadro. Esse caminho foi planejado para conduzir ao bosque de livre organização vegetal e para oferecer uma vista ideal da casa. A pavimentação que se encontra entre as árvores forma uma clareira em meio ao bosque, criando um espaço de estar. A partir dele visualiza-se a perspectiva da casa através de um filtro formado pela verticalidade dos troncos, em contraste entre a escura vegetação e o branco volume edificado.

No terraço-jardim um volume fechado se alonga frontalmente, restringindo suas visuais em direção ao jardim de lazer e evidenciando a barreira que divide o jardim em zona pública (jardim anterior) e zona privada (jardim posterior). Na cobertura encontra-se a essência da integração entre jardim e arquitetura. A idéia da substituição do telhado inclinado pela cobertura plana e utilizável era uma inovação para a época. Uma forma de obter um precioso espaço de estar e contemplação ao ar livre e alto do solo, com uma visão aérea do entorno. Segundo Fariello (2000, p. 319), uma forma de recuperar o terreno natural ocupado pela edificação.

† terraço-jardim mantém a malha que ordena a casa, mas se desprende parcialmente da simetria por ela caracterizada, evidente na fachada frontal. De qualquer maneira, a composição formal prevalece pela simetria das formas curvas de um volume que se alinha por um dos eixos, o mesmo da janela-quadro do jardim posterior. A janela-quadro da cobertura ocupa a posição sobre outro eixo paralelo a esse e, com a finalidade de emoldurar a silhueta de Paris, levando o terraço a uma conotação de belvedere. Se Le Corbusier utilizou na Villa Stein alguma vegetação florífera sazonal, provavelmente a tenha colocado nas floreiras da cobertura. No jardim térreo somente foram introduzidas espécies perenes, com o intuito de proporcionar baixa manutenção.

\section{ANALOGIA PICTÓRICA}

Segundo Fariello (op. cit., p. 318), o jardim da Villa Stein foi pensado para satisfazer as necessidades dos usuários e para participar da configuração espacial e formal da edificação, muito mais do que para obedecer a algum modelo pictórico. Para Curtis (1987, p. 72), Le Corbusier foi um arquiteto purista que enriquecia seus desenhos com curvas, o que se pode observar em muitas de suas obras, na arquitetura, pintura ou tapeçaria. 
Uma análise da composição plástica e formal de uma tapeçaria desenvolvida por Le Corbusier para o Palácio da Justiça em Chandigarh pode demonstrar, claramente, como as mesmas formas e composições utilizadas no desenho do jardim da Villa Stein também foram trabalhadas nessa obra para a Índia. Apesar de ter sido elaborada muitos anos mais tarde, Le Corbusier aproveitou o mesmo tema, abstraindo formas já incorporadas em sua obra. É impressionante a similaridade no jogo das formas, a predominância do retilíneo, do geométrico, da composição formal, dos eixos. Podemos observar, ainda, a alternância de cheios e vazios pelas representações das massas, dos escuros, fechados, em contraste com os claros, abertos. A indução dos caminhos, representados pelos retângulos estreitos e compridos, claros e escuros. As texturas, tal qual a vegetação do jardim, densa ou mais rala, ou compreendida volumetricamente, alta ou baixa. E a intencional curva, um momento de liberdade, mesmo não sendo uma forma aleatória, transcende à regrada geometria do equilíbrio calculado, dando asas à imaginação. Uma tendência que, ao longo do tempo, foi se intensificando nas obras de Le Corbusier, extrapolando a planta e alcançando a volumetria, o que culminou na capela de Ronchamp - Notre Dame du Haut - em 1955.

A planta de cobertura da Villa Stein-de Monzie tem uma semelhança com a composição da obra cubista Guitarra e fruteira de 1921, do artista plástico Juan Gris. Conforme Marchán (1987, p. 40), Le Corbusier empregava, na elaboração de seus projetos, o mesmo procedimento que Gris empregava na organização de suas pinturas: partindo do geral ao particular, convertia em concreto o abstrato, transformando os elementos do intelecto. No caso do pintor, sua imaginação se concretizou em uma tela. Esta pode ter gerado outras abstrações, proporcionando semelhanças na composição da cobertura da Villa Stein.

Para Curtis (op. cit., p.81), decompor as formas de Les Terrasses em um desenho axonométrico significa captar rapidamente como cada um dos níveis é diferente dos demais e como os planos reais e os ilusórios se condensam com objetos curvos para formar o equivalente a uma natureza morta purista, todavia, agora habitável. Essa abstração pode ser observada na obra de Le Corbusier, Natureza morta com uma pilha de pratos e um livro, de 1920. Segundo Baker (1994, p. 311), na tela de Le Corbusier, o contraste das formas primárias e maciças com o volume puro do fundo e de todos entre si, traduz-se na imediata identificação dos distintos elementos. Essa distribuição corrobora com a idéia de Le Corbusier acreditar que a justaposição de formas primárias desempenha um papel essencial também na experiência sensorial da arquitetura.

\section{ANALOGIA MOBILIÁRIA}

As formas básicas de composição do desenho da casa e do jardim da Villa Stein-de Monzie repetem-se e reaparecem em obras diversas do arquiteto. A predominância do geométrico, retilíneo e a introdução de alguma linha curva para suavizar o ângulo reto, também está presente no projeto de sua conhecida cadeira chaise-longue desenvolvida 
em 1928, em colaboração com Pierre Jeanneret e Charlotte Perriand e exposta no Salão d'Automne (1929), em Paris.

A cadeira apresenta dois elementos independentes, o suporte e a estrutura. $\bigcirc$ suporte é sua base. Base no sentido de sustentação e base no sentido formal, por suas linhas retilíneas e composição geométrica. Sobre essa base se apóia a estrutura com sua majestosa e anatômica curva, contrastando com o retilíneo e proporcionando conforto a seu usuário, resultado de um profundo estudo de ergonomia. Novamente é a sensual curva que se apóia, que se ancora na rigidez formal, na linha racional do modernismo. Trata-se da sinuosidade como uma pitada de energia vibrante sobre o elemento estático, transformando a síntese conceitual.

\section{ANALOGIA COM OUTRAS OBRAS}

Existe uma correspondência entre o sistema proporcional da retícula da Villa Stein-de Monzie e da Villa Foscari (Malcontenta) de Andrea Palladio, de 1565, visitada por Le Corbusier em sua viagem de estudos ao Mediterrâneo. Rowe (1995), em The mathematics of the ideal villa, estabelece um paralelo entre os projetos de Le Corbusier e de Palladio, enfatizando as proporções adotadas em ambos. Se essa influência gerou o traçado da retícula do desenho da casa em Graches, em continuidade, também criou o do jardim.

Já o uso do recurso das janelas-quadro recorda as aberturas retangulares que Le Corbusier havia visto nas ruínas romanas, em sua viagem de 1911, que, como telas, condensavam as visuais da natureza. Segundo Curtis (op. cit., p. 80), também os terraços de cobertura e as janelas horizontais se combinam com uma complexidade espacial nascida a partes iguais da pintura purista e das ruínas antigas das habitações sem teto, que Le Corbusier havia desenhado na Villa Adriana.

A idéia da janela quadro do terraço-jardim da Villa Stein já havia sido utilizada pelo arquiteto na Villa Le Lac, em 1925, no muro junto da água, para emoldurar a paisagem do lago e dos Alpes, e foi reaproveitada, muitas vezes, em seus projetos. Na Villa Meyer, de 1925, na Villa Weissenhof em Stutgard de 1927 e, posteriormente, na Villa Savoye, de 1928, entre outros. Em alguns projetos, existe uma mesa junto da janela que, conforme Curtis (op. cit., p. 75), era, seguramente, uma imitação retirada do monastério de Ema. Essa idéia também foi transportada para as villas mencionadas, e, na Villa Stein-de Monzie foi considerado que o elemento construído no jardim posterior, não-detalhado no projeto, também devesse contemplar uma mesa junto da janela-quadro.

Incluir elementos da história nos projetos era uma constante para Le Corbusier, pois, conforme Curtis (op. cit., p. 84), sabia, igual a Palladio, que a modernidade só tem valor se está enraizada na sabedoria dos antigos e a tradição somente se mantém viva mediante a transformação constante. Mas foi em relação a Maison La Roche-Jeanneret, de 1923, que Le Corbusier observou: "estão aqui, vivos de novo diante de nossos olhos modernos, os acontecimentos da história" e foi o próprio La Roche quem acrescentou: "o arquiteto possui uma admirável capacidade para enlaçar a nossa época com as precedentes." 
Ainda conforme Curtis (op. cit., p. 81), na casa Favre-Jacob, de 1912, Le Corbusier já havia usado a idéia do caminho para o automóvel que chega a uma grande fachada, seguindo por uma seqüência de espaços curvos e retangulares que davam a um terraço e a um jardim posterior, voltando a usá-lo em Garches.

A implantação da Maison Cook, de 1926, segundo Curtis (op. cit., p. 75), ocorreria na diagonal em relação ao terreno, oferecendo espaço suficiente para um jardim dianteiro e outro posterior. Essa solução se repetiu na implantação da Villa Stein-de Monzie, com a diferença de essa ainda possuir uma estreita faixa de terreno entre a casa e a divisa, o que não acontece na Maison Cook, edificada de divisa a divisa. Essa casa ainda se assemelha à casa Stein, pela presença de um caminho reto para veículos e de um sinuoso, ancorado no retilíneo, além da presença do terraço de cobertura.

Em 1922, Immeubles-villas introduziu, na arquitetura, uma idéia inovadora de jardim suspenso em um edifício residencial urbano: que cada apartamento pudesse ser considerado uma pequena casa com jardim, independentemente do pavimento em que se encontrasse. Isso era possível pela introdução de um amplo terraço individual, transformado em jardim. Era uma contribuição para tornar as cidades mais verdes, principalmente em bairros de alta densidade. Já anteriormente, em estudo para a Maison Citrohan, de 1920, havia aparecido uma idéia de solário, aproveitando o terraço de cobertura. Na Immeubles-villas essa idéia, acrescentada de vegetação, estava sendo implantada em edificação multifamiliar, com a intenção de possibilitar a todos o direito de sol, ar e vegetação.

O uso da cobertura como jardim está incluído entre os cinco pontos da nova arquitetura estabelecida por Le Corbusier e Pierre Jeanneret, que a partir de então passou a fazer parte do estilo de construção desses arquitetos. No projeto da Villa Meyer, de 1925, já existe um suntuoso jardim suspenso com ampla área de lazer e piscina, evidenciando a importância do espaço criado. Também a existência de um espaço de jardim, com pé direito duplo formando um oco no volume cúbico, assemelha-se à idéia de penetração do jardim no volume da casa em Garches, que se dá pelos terraços em vários níveis.

A Villa Savoye, de 1929, demonstra a força e a continuidade das idéias lançadas com determinação a partir do projeto da Villa Stein-de Monzie. Essa casa se tornou a predileta do arquiteto e a mais famosa. Conforme Brown (op. cit., p. 25), nesse projeto Le Corbusier colocou em prática suas idéias sobre o jardim moderno, e, entre elas, duas teorias aparentemente contraditórias: a primeira, a da Immeuble Villa, com o intuito de proporcionar um ideal de sol, ar e vegetação e, a segunda, a da "ansiedade quase patológica" que sentia o arquiteto pelo fato de viver em contato com o solo. "Quando alguém está em pé no campo, não consegue ver muito longe", escreveu Le Corbusier, "E mais, o solo é insalubre, úmido, etc.[...] em conseqüência, o autêntico jardim da casa não há de estar ao nível do solo, mas sim 3,5m por cima dele: é o jardim suspenso, cuja superfície é seca e saudável e do qual se tem uma boa visual".

Para o arquiteto, o terraço de cobertura transformado em jardim substituía o jardim do solo, que deveria ser utilizado para as práticas esportivas, a circulação dos automóveis e também para ser contemplado a partir dos terraços da casa. 
Le Corbusier teve a preocupação, nas Villas Meyer, Stein-de Monzie, Savoye e outras, de deixar os jardins de cobertura mais intimistas, protegendo-o das vistas do caminho de acesso, por paredes ou por um volume, como no caso da Villa Stein e da Villa Savoye.

\section{DEFINIÇÃO GRÁFICA DA PROPOSTA}

A proposta gráfica aqui apresentada, para o jardim em Garches, foi definida pela análise da composição dos espaços, pela decodificação das informações obtidas no projeto de Le Corbusier e da construção de um modelo tridimensional, incluindo as partes do projeto que carecem de informação, ou seja, das quais as referências são incompletas. Essas partes tiveram sua elaboração baseada na análise e interpretação dos elementos em planta e em outros projetos de Le Corbusier, estabelecendo, por meio de uma hipótese, a reconstrução formal do jardim (Figura 1).

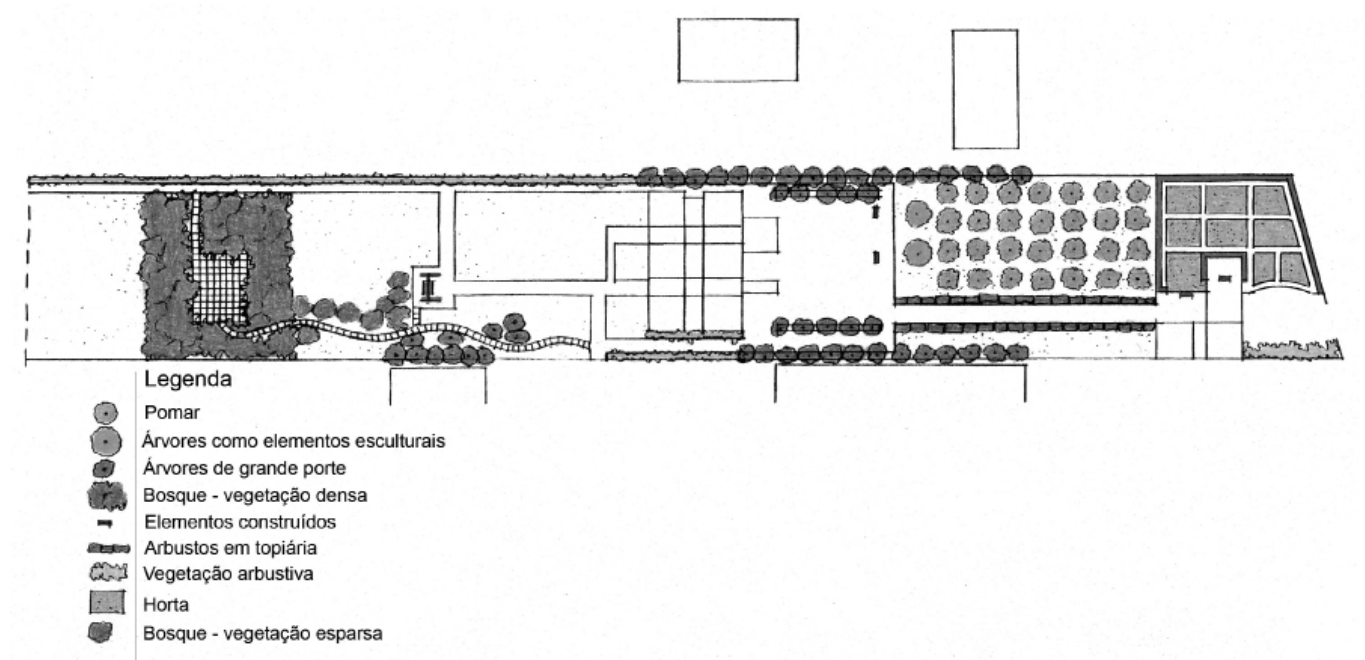

Figura 1: Distribuição da vegetação

Crédito: Desenho da autora

ritmo da casa 2:1:2:1:2 que define os eixos, tanto da casa quanto do jardim, orientam o desenho dos caminhos da frente da casa e dos fundos, o acesso pela porta principal, as visuais das janelas-quadro, tanto da janela dada como suposta no nível do solo quanto da janela no terraço de cobertura (Figuras 2 e 3).

A composição volumétrica da casa, caracterizada como um sólido geométrico recortado e parcialmente vazado, também está presente no jardim pela alternância de cheios e vazios, ou seja, de massas de vegetação e de áreas abertas, gramadas ou pavimentadas (Figura 4).

Em análise do traçado projetual pode ser observado, ainda, que o traçado regulador das fachadas e sua geometria se encontra representado no paisagismo, não só pelos eixos que orientam o desenho dos caminhos, mas também pela modulação e da 
proporção de ouro, como o bosque e a pavimentação de sua clareira, a janela-quadro do solo e a esplanada frontal.

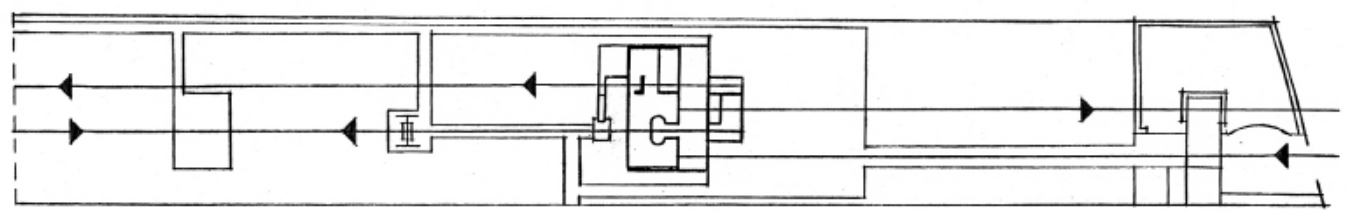

Figura 2: Planta baixa apresentando os eixos diretrizes do projeto e respectivas visuais

Crédito: Desenho da autora

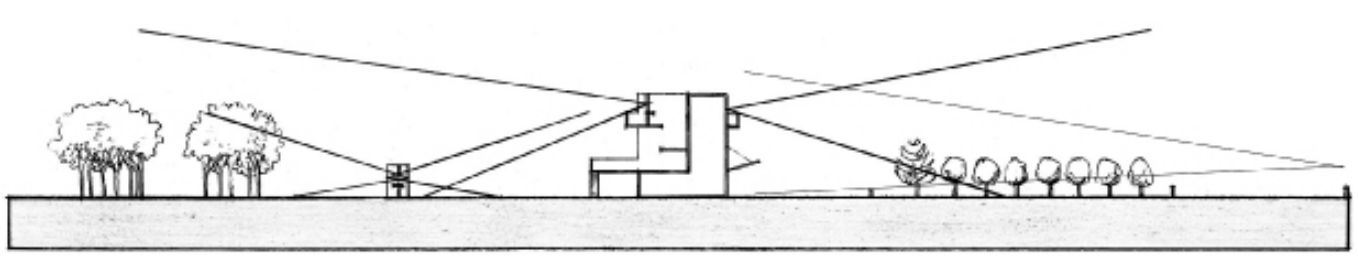

Figura 3: Corte longitudinal apresentando as visuais referenciadas pelos eixos projetuais Crédito: Desenho da autora

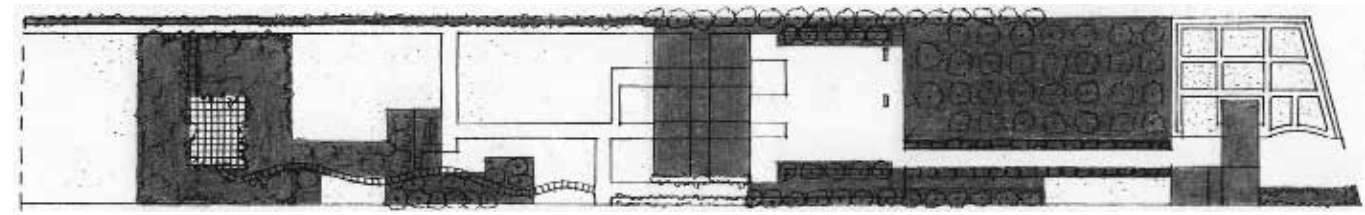

Figura 4: O projeto do jardim é definido pelo ritmo de cheios e vazios Fonte: Desenho da autora

Analisando a tipologia vegetal, verifica-se a presença de espécies diferenciadas pela altura, densidade, estrutura e forma de plantação. Pode-se observar, claramente, o agrupamento intencional de determinada tipologia, formando maciços vegetais, com

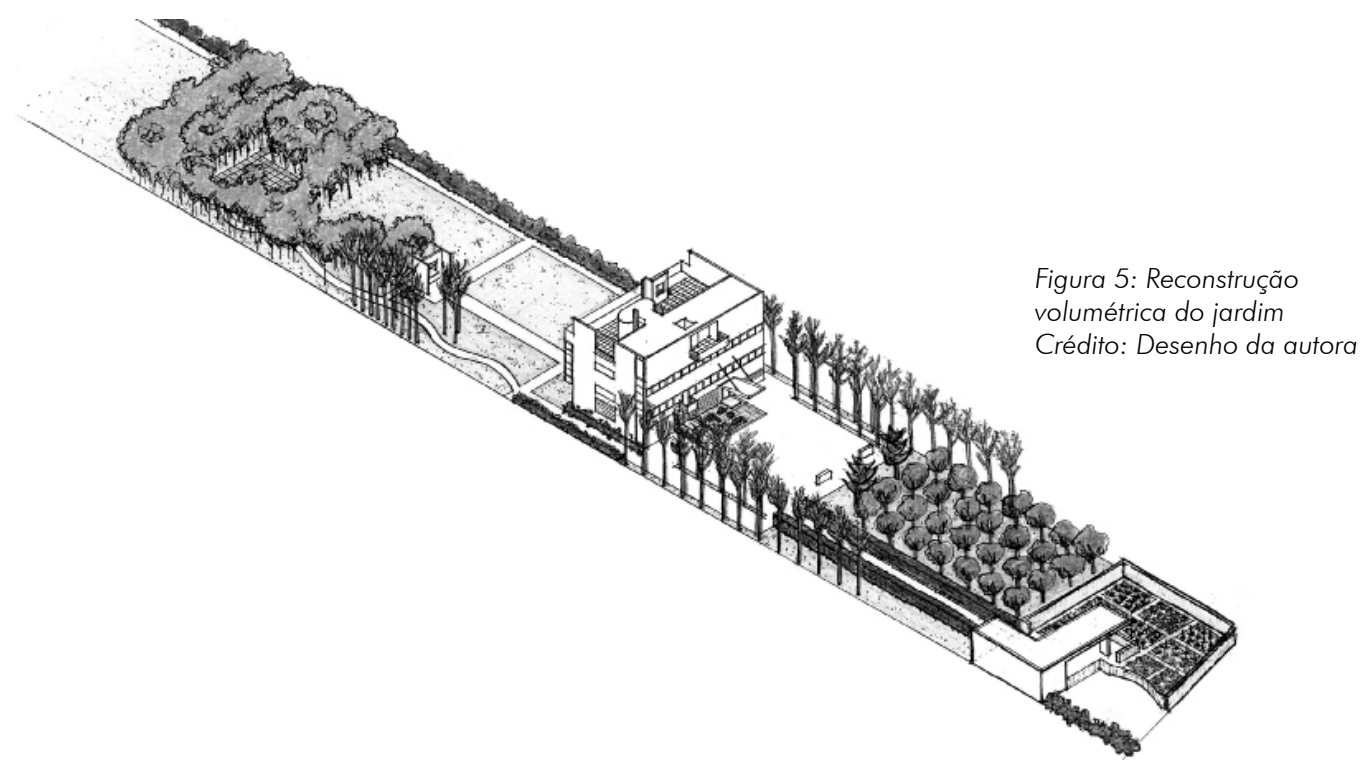


funções específicas de utilidade. Nesse sentido, estão projetados a horta, o pomar e as árvores de grande porte, formando uma barreira visual com uma plantação reticular ou em linha, ou formando uma área de lazer com uma plantação mais livre a modo de bosque. Esse estudo possibilitou a definição volumétrica das espécies que, por sua vez, possibilitaram uma leitura volumétrica do jardim e a elaboração de um modelo tridimensional para uma melhor compreensão das intenções projetuais (Figura 5).

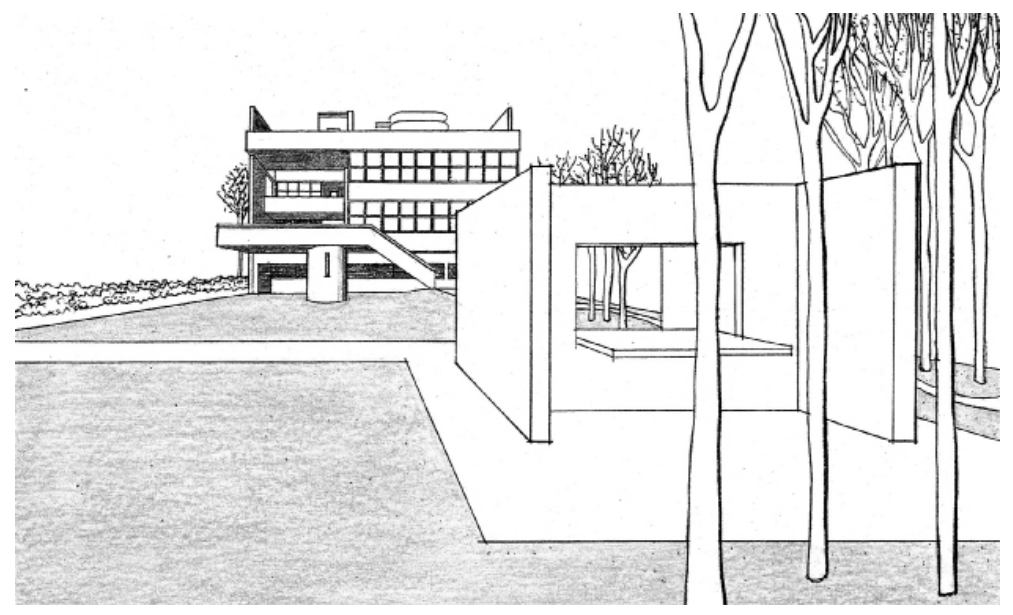

Figura 6: Proposta para o elemento arquitetônico do jardim enquadrando a casa Crédito: Desenho da autora

Foi desenvolvida uma proposta espacial para a possível janela-quadro com mesa anexa, para que se pudesse compreender o efeito das visuais proporcionadas através dela, em direção a casa e também em direção ao bosque posterior, enquadrando fragmentos da paisagem como quadros de cenas estáticas (Figura 6 e 7). A retícula, os eixos e o ângulo reto do racionalismo moderno são os principais elementos abstratos que governaram o projeto da casa e do jardim.

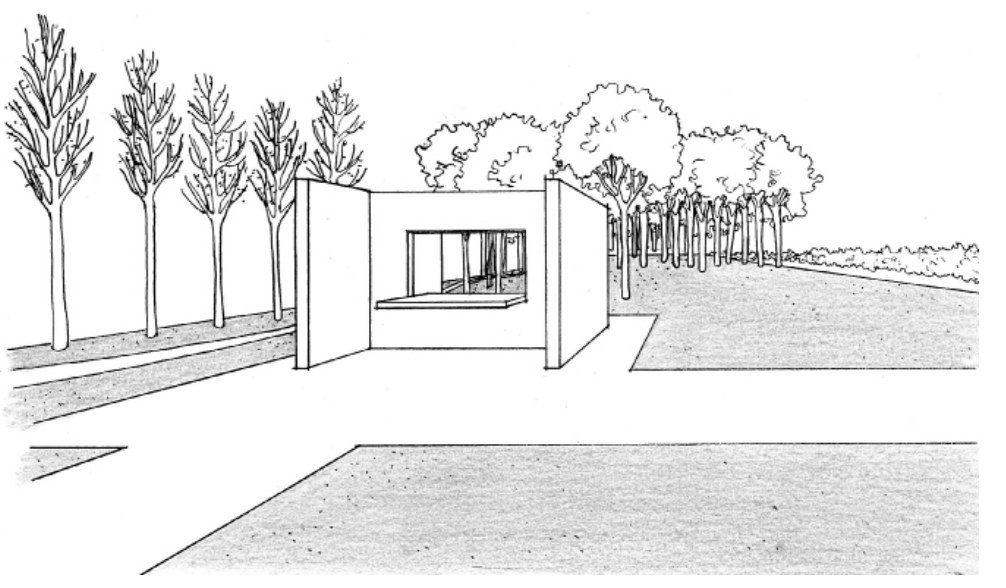

Figura 7: Proposta para o elemento arquitetônico do jardim enquadrando o bosque posterior Crédito: Desenho da autora

\section{CONCLUSÃO}

O jardim da Villa Stein-de Monzie teve seu embasamento nas abstrações geométricas dos eixos e proporções, dos cheios e vazios, em que o projeto de arquitetura orientou o traçado do paisagismo. $\bigcirc$ naturalismo e a relação pictórica ficaram em segundo 
plano. Utilizando esses princípios, segundo Fariello (op. cit., p. 321), Le Corbusier voltou a examinar seus conceitos básicos de espaços de estar, circulação, visuais e relação com a natureza.

"O olho proporciona a mediação entre a ordem construída e a sábia desordem da natureza; o olho narrador conduz o arquiteto da terra ao céu e do cubo à nuvem, facilitando o trânsito entre a geometria e a paisagem." (GALIANO, 1987, p. 28). Le Corbusier pensa com os olhos e constrói seus espaços com imagens e estas se encadeiam como se estivessem sendo narradas. As visuais estão em constante estudo em suas obras: da edificação ao jardim, do jardim à edificação. Na Villa Stein-de Monzie os eixos geradores da casa também são os eixos das principais visuais. $\bigcirc$ acesso retilíneo de veículos, traçado sobre o eixo que conduz à garagem, não prevê surpresas, proporciona uma visual integral da casa logo no início de seu trajeto. No transcorrer do percurso, uma sensação de fechamento produzida pelas massas de vegetação define ainda mais o direcionamento da visual. Outro eixo visual se define no eixo do acesso principal da casa, a partir da janela-quadro localizada na cobertura, em direção ao jardim posterior. É uma visual produzida intencionalmente, formal e disciplinar. E, em outro eixo, a janela-quadro junto do solo, proposta neste trabalho como provável elemento edificado do jardim, direciona a visual do jardim em direção a casa, emoldurando-a e valorizando-a. Um terraço frontal proporciona uma visual ampla do jardim público e, o terraço de cobertura, uma visual ampla do jardim privado. As visuais direcionadas, no entanto, são conseguidas a partir do acesso ao lote e a partir das janelas-quadro, que focalizam um detalhe e emolduram, de forma premeditada, um trecho da paisagem, como uma natureza morta.

A introdução de um jardim de cobertura, como novidade arquitetônica, possibilitou a elaboração do projeto em Garches, de forma a dividir o jardim em três diferentes categorias, conforme sua função. $O$ terraço-jardim é o elo entre os outros dois e também entre o jardim e a arquitetura, pois traz a paisagem para dentro de casa. Além disso, é o mais nobre, o que se eleva aos céus, o mais saudável, o que proporciona as melhores visuais, o mais antrópico e íntimo. Essa idéia já vinha sendo trabalhada há alguns anos, por Le Corbusier, como em Immeuble-villas e no projeto da Villa Meyer, mas foi com a Villa Stein-de Monzie que teve uma maior repercussão.

O jardim no nível do solo era considerado como um jardim terreno, no sentido filosófico da palavra. Essa interpretação mundana justifica a grande valorização do jardim de cobertura, dos quais sempre encontramos, em se tratando de projetos de Le Corbusier, farta documentação de detalhes, o que não acontece em relação ao jardim térreo, ao entorno edificado. Nesse contexto, o jardim da Villa Stein se torna uma referência à pesquisa do paisagismo moderno. 


\section{Bibliografia}

BAKER, Geoffrey H. Le Corbusier: Análisis de la forma. Barcelona: Gustavo Gilli, 1994.

BENTON, Tim. Les villas de Le Corbusier et Pierre Jeanneret. Paris: Phippe Sears, 1984.

BOESIGER, W.; GIRSBERGER H. Le Corbusier 1910-1965. Barcelona: Gustavo Gilli, 1971.

BOESIGER, W.; STONOROW, O. Le Corbusier et Pierre Jeanneret 1910-1929. Zurique: Ártemis, v. 8, 1973.

BROOKS, H. Allen. The Le Corbusier archive. Paris: Foundation Le Corbusier, v. 3, 1982.

BROWN, Jane. El jardín moderno. Barcelona: Gustavo Gilli, 2000.

CURTIS, William J. R. Le Corbusier - Ideas y formas. Madri: Hermann Blume, 1987.

FARIELLO, Francesco. La arquitectura de los jardines: De la antigüedad al siglo XX. Madri: Mairea-Celeste, 2000.

GALIANO, Luis F. La Mirada de Le Corbusier: Hacia una arquitectura narrativa. AV Monografias: Le Corbusie, Madri, v. 1, n. 9, p. 28-35, 1987.

IMBERT, Dorothée. The modernist garden in France. Londres: Yale University Press, 1993.

MARCHÁN, Simón. Composición y proyecto: Modernidad y clasicismo en la obra temprana. AV Monografias: Le Corbusier, Madri, v. 1, n. 9, p. 36-43, 1987.

ROWE, Colin. The mathematics of the ideal villa and other essays. Cambridge: MIT Press, 1995. 